\title{
On auroral dynamics observed by HF radar: 1. Equatorward edge of the afternoon-evening diffuse luminosity belt
}

\author{
M. Uspensky ${ }^{1,4}$, P. Eglitis ${ }^{1,2}$, H. Opgenoorth ${ }^{1,2}$, G. Starkov ${ }^{3}$, T. Pulkkinen ${ }^{1}$, R. Pellinen ${ }^{1}$ \\ ${ }^{1}$ Finnish Meteorological Institute, Geophysical Research, PO Box 503, FIN-00101, Helsinki, Finland \\ ${ }^{2}$ Swedish Institute of Space Physics, PO Box 537, 75121 Uppsala, Sweden \\ ${ }^{3}$ Polar Geophysical Institute, Apatity, Russia \\ ${ }^{4}$ Murmansk State Technical University, Sportivnaya 13, Murmansk, Russia
}

Received: 3 May 2000 / Revised: 20 August 2000 / Accepted: 12 September 2000

\begin{abstract}
Observations and modelling are presented which illustrate the ability of the Finland CUTLASS $\mathrm{HF}$ radar to monitor the afternoon-evening equatorward auroral boundary during weak geomagnetic activity. The subsequent substorm growth phase development was also observed in the late evening sector as a natural continuation of the preceding auroral oval dynamics. Over an $8 \mathrm{~h}$ period the CUTLASS Finland radar observed a narrow (in range) and persistent region of auroral F- and (later) E-layer echoes which gradually moved equatorward, consistent with the auroral oval diurnal rotation. This echo region corresponds to the subvisual equatorward edge of the diffuse luminosity belt (SEEL) and the ionospheric footprint of the inner boundary of the electron plasma sheet. The capability of the Finland CUTLASS radar to monitor the E-layer SEEL-echoes is a consequence of the nearly zero E-layer rectilinear aspect angles in a region $5-10^{\circ}$ poleward of the radar site. The F-layer echoes are probably the boundary blob echoes. The UHF EISCAT radar was in operation and observed a similar subvisual auroral arc and an F-layer electron density enhancement when it appeared in its antenna beam.
\end{abstract}

Key words: Ionsophere (ionospheric irregularities) Magnetospheric physics (auroral phenomena;

magnetosphere-ionosphere interactions)

\section{Introduction}

Efforts to find ways for radar monitoring of the auroral forms and/or auroral boundaries using ionospheric plasma density irregularities as tracers has been an attractive task for researchers from at least the mid

Correspondence to: $\mathrm{M}$. Uspensky e-mail: mikhail.uspensky@fmi.fi forties (Herlofson, 1947). The positive steps in this field for the HF band were made by Bates et al. $(1965,1966$, 1969) and Moller (1974), who showed the existence of the radio wave scattering belt and the intense irregularity curtains which include the visual auroral belt. In general, there was a reasonable correspondence between the location of the visual auroral belt and the belt of the auroral radar backscatter. However, closer comparisons gave results ranging from total mutual coincidence to total disconnectivity.

Even the better resolution of VHF radars as compared with HF did not give the early researchers a chance to understand the possibilities of auroral boundary monitoring by radars. They found a general common behaviour in the diurnal, latitudinal and altitudinal coverage of the aurora and the auroral radar backscatter and also a similar reaction to geomagnetic activity (Bagaryatsky, 1961; Hultqvist and Egeland, 1964). On the other hand, one attempt of a detailed comparison of the aurora and the auroral radar backscatter exhibited rather the absence of mutual spatial coincidence (Gadsden, 1967).

Studies in the seventies mark a change in understanding of the coupling between visual and radar aurora. They showed that the bright aurora and the auroral radar backscatter prefer to be in close spatial contact and/or common motion (Greenwald et al., 1973; Tsunoda et al., 1974, 1976). A number of papers that described the pre-substorm, substorm or post-substorm behaviour of the aurora and the auroral radar backscatter supported or even fitted well within a scheme (Ecklund and Unwin, 1971; Tsunoda et al., 1976; Tsunoda and Fremouw, 1976; Uspensky et al., 1982, 1983, 1992; Starkov and Uspensky, 1988). Better than other auroral observations, radars can detect and follow the auroral arcs particularly at the equatorward portion of the auroral oval and also during fast auroral motions (Greenwald et al., 1973, 1975, Tsunoda and Fremouw, 1976; Starkov and Uspensky, 1988 and references therein). Those observations led to a conclusion that the condition for an irregularity excitation near the auroral forms most frequently are the typical average 
ones observed in the polar ionosphere. Indeed, the backscatter can originate in an area with both a moderate electric field and with moderate electron density. We believe that a reasonable conclusion from a number of past studies is that both the density and electric field can be of moderate or enhanced value, but both need to be above a threshold level.

The history of auroral and auroral radar backscatter studies has made a complete circle with respect to ideas of how the backscatter relates to the aurora. The first thoughts were that the auroral radar backscatter somehow represents the auroral forms even though it can be modified by aspect-angle effects (Herlofson, 1947). The second step in the history was marked by numerous findings where the correlation of the two phenomena was limited (see e.g. Egeland, 1973 and references therein) or there was nearly no spatial coincidence between the aurora and the radar aurora (Gadsden, 1967). It seemed then that the aurora and the radar aurora did not relate to each other. At the present time, following satellite images of the auroral oval with bright auroral forms embedded in an extensive background of diffuse luminosity (Anger and Lui, 1973; Lui et al., 1973, 1982), we again can see the auroral radar backscatter representing the aurora. However the auroral radar backscatter is not a tracer of the bright auroral forms, arcs or the rays. The irregularities and the auroral radar backscatter mainly originate in areas covered with a moderately structured or homogenous diffuse luminosity (Uspensky and Starkov, 1987). However, exceptions do exist, e.g. in the equatorial electrojet, the field-aligned irregularities can be excited without any related particle precipitation and auroral luminosity.

The remaining question in the history of these two high-latitude phenomena was why the auroral radar backscatter avoids the auroral arcs where the condition to excite e.g. the gradient-drift irregularities (Knox, 1964) at first glance seems to be fulfilled. Indeed, a-few$\mathrm{mV} \mathrm{m}^{-1}$ poleward electric fields are observed (de la Beaujardiere et al., 1977), which can be co-located with the poleward directed electron density gradient. The increased electron density in the auroral arc provides an opportunity for increased radar sensitivity which allows the detection of even weaker electron density fluctuations than typically observed outside arcs. For comparison, 1-m auroral irregularities and the related backscatter can be detected sporadically under similar conditions outside auroral arcs, e.g. when the electric field is up to $5-15 \mathrm{mV} \mathrm{m}^{-1}$ (Kustov et al., 1989). Grabowski et al. (1985) also noted that the 21-m irregularities were detected in the SAFARI-experiment when the electric field was only $7 \mathrm{mV} \mathrm{m}^{-1}$. In both examples, there were no arguments to suggest that the electron density and its gradients were more than just moderate. One possible explanation of a small-scale irregularity damping inside auroral arcs is recombination damping, which probably can be an important factor under conditions with increased electron density and decreased electric field. However, as a whole, the question of why the backscatter avoids the auroral arcs remains open and could be the subject of future studies.
Over the last decade, with the expansion of the SuperDARN HF radar network over the globe (Greenwald et al., 1995), a significant amount of ordered data sets of E- and F-region irregularities has been accumulated. It creates new advanced possibilities for studies in the HF band (as well as for radar-optical ones) and has revealed a few specific features of the auroral radar backscatter. One such feature is a close co-location of the $630 \mathrm{~nm}$ cusp red line aurora and HF auroral radar backscatter in the late morning and early afternoon (Rodger et al., 1995; Yeoman et al., 1997; Milan et al., 1998, 1999), which was found even during a change of $\mathrm{HF}$ propagation modes. One more feature is often observed by the Finland CUTLASS radar during the winter half of the year. (The Finland CUTLASS radar and the Iceland CUTLASS radar form the most eastward pair of the SuperDARN network.) That feature is a persistent, long-lived and narrow in range region of afternoon-evening echoes, which slowly moves equatorward. Due to their characteristic image in the range-time display we will call them ribbon echoes. Such echoes are more often seen during moderate or weak geomagnetic activity.

Our task is to study and interpret an 8-h long interval of ribbon echoes. The event under consideration occurred during the afternoon and evening local time sector of 17 November, 1996. For approximately $15 \mathrm{~h}$ the geomagnetic conditions were nearly quiet until an isolated double substorm onset occurred (see Karlsson et al., 2000). In the framework of this study, we concentrate our attention mainly on the prolonged quiet-time and pre-substorm echo dynamics, the conditions on how and where the echoes originate as well as the relationship between the auroral radar backscatter and the equatorward auroral and/or ionospheric boundaries.

We introduce the term "ribbon echoes" to emphasise the unusual feature of the observed echoes. The feature described is long-lived and gradually moves equatorward always being mainly of 1 or 2 range gates slant range coverage. The ribbon form of the echoes is the external signature or image of how these echoes look like on the range-time display.

The attractive feature of the event was that from the early afternoon until late evening magnetic local time the Finland CUTLASS radar observed such a persistent and narrow (in range) region of echoes nearly simultaneously at two frequencies of 10 and $12.4 \mathrm{MHz}$. The strips exhibited a rather slow, $30 \mathrm{~ms}^{-1}$, gradual equatorward motion until they became part of the subsequent substorm development.

Our modelling allows us to monitor a narrow region of E-layer echoes, which is a consequence of the nearly zero E-layer aspect angles in a region $5-10^{\circ}$ poleward of the Finland CUTLASS radar site. During weak and moderate geomagnetic disturbances the equatorward edge of the diffuse luminosity belt is located only in this area. Then only in the E-layer leading edge (where the electron density isolines run normal to the radar rays) do the ray trajectories not bend. It means that the ionospheric refraction does not turn the radar ray 
trajectories away from the already existing correct geometry for strong orthogonal backscatter. Thus, the Finland CUTLASS radar has the highest sensitivity in its field-of-view at the location of the horizontal ionospheric gradients. In other words, for our specific backscatter geometry (i.e. for the Finland CUTLASS radar site and for the E-layer altitudes), the refraction is a negative factor which obscures the backscatter. This is completely opposite to more typical cases, e.g. for the Flayer where the refraction is a positive factor necessary to achieve the right othogonality conditions.

The observed features of the echoes together with the radar line-of-sight geometry, as well as the results of the comparison with the model auroral boundaries and with the supported incoherent scatter data, form the basis of our conclusions on the nature of ribbon echoes. We found that ribbon echoes originate at the equatorward edge of the auroral diffuse luminosity belt and the leading edge of the related auroral E-layer in the vicinity of the main ionospheric trough. During the early afternoon (when the E-layer leading edge is probably masked by solar-produced ionisation) the echoes originate at the Flayer altitudes in the area known as the ionisation boundary blob, which forms the poleward boundary of the main ionospheric trough (Tsunoda, 1988).

Since the ribbon echoes trace the subvisual equatorward boundary of the diffuse luminosity belt and the equatorward boundary of the auroral oval, we can consider them as the ionospheric footprint of the inner boundary of the electron plasma sheet. Taking into account the nature of the echoes, we call them the SEEL-echoes, i.e. the echoes from the subvisual equatorward edge of the auroral oval and its diffuse luminosity belt. Our suggestions regarding these SEEL-echoes and the model auroral boundaries (Starkov, 1994) are well supported by subsequent visible signatures in the substorm growth-phase development, which was registered in the late evening sector after the start of the substorm growth phase around 1900 UT (2200 MLT).

\section{Instrumentation}

The basic data set discussed is collected by the HF CUTLASS coherent scatter radar facility, comprising two radar installations, located at Hankasalmi, Finland $\left(62.3^{\circ} \mathrm{N}\right.$ and $\left.26.6^{\circ} \mathrm{E}\right)$ and at Pykkvibaer, Iceland $\left(63.9^{\circ} \mathrm{N}\right.$ and $\left.19.2^{\circ} \mathrm{W}\right)$. The CUTLASS radars are maintained and operated by Leicester University (UK) in co-operation with the Finnish Meteorological Institute and the Swedish Institute of Space Physics. The radar fields-ofview cover a spacious common area for distant echoes but they are at best only partially overlapping at near ranges for short-distance F-layer echoes and E-layer echoes. The afternoon-evening short-to-moderate distant E-and F-layer echoes in the vicinity of and poleward of the main ionospheric trough are inside the area of our interest here. More on the radar as well as the SuperDARN network specification can be found in papers by Greenwald et al. (1983, 1985, 1995).
The radar measurements on November 17, 1996 were part of a multi-instrumental campaign which included UHF EISCAT observations parallel to the magnetic field and numerous ground-based and multi-spacecraft satellite instruments. Where it is appropriate we will involve the data from these instruments in the discussion and interpretation. Of particular importance are the instruments of the MIRACLE (Magnetometers-Ionospheric Radars-Allsky Cameras Large Experiment) network, which is a two-dimensional instrumental network constructed for studies of auroral electrodynamics from subauroral to polar cap latitudes. The MIRACLE network is maintained and operated in wide international co-operation under the leadership of the Finnish Meteorological Institute.

The solar-wind-controlled double substorm onset (which occurred during this day at 1930 and 1957 UT) has already received detailed attention in Karlsson et al. (2000), although there was no inclusion and interpretation of the CUTLASS data. Our analysis will mainly concentrate on the 8-h quiet-time interval where the persistent ribbon echoes were present before the full substorm development.

\section{Geophysical background}

The IMAGE magnetometer network data displayed in Fig. 1 shows the main interval of interest of $12-19$ UT is embedded in nearly quiet geomagnetic conditions. (The location of the magnetic observatories as well as the collected area of the Finland and Iceland CUTLASS radars is shown in Fig. 2.) The IMAGE AE-index does not exceed $100 \mathrm{nT}$ being mainly 50-70 nT. Only before noon are there moderate and irregular geomagnetic fluctuations (AE 100-150 nT), which are better observed by the polar cap stations (LYR, HOR, HOP and BJN) than at lower latitudes. For the lower latitude stations the magnitude of the magnetic disturbance is less than $30 \mathrm{nT}$. The East-Siberian magnetometers in the magnetic midnight sector also did not detect any significant disturbance in the interval mentioned.

The start of the substorm growth phase in the geomagnetic data can only be identified around 1910 1913 UT. This is close to the time when the FMI digital all sky camera (Syrjäsuo, 1997) in Muonio detected the first signature of a faint growth-phase auroral arc. It seems important to note that the first very slight luminosity effects at the northern horizon of the Muonio film all sky camera data can be detected around 1857$1858 \mathrm{UT}$. This is around $10 \mathrm{~min}$ after WIND observed a negative IMF $B z$-turn and 5-6 min later than the start of the F-layer echo equatorward motion as can be seen from the Finland CUTLASS radar data (for more details see later). It was unfortunate that no all sky cameras further north were able to make auroral observations, and support these findings, due to extensive cloud cover.

Changes in the IMF as observed by the WIND satellite for the evening sector (after about 1700 UT) are well matched to the sequence of substorm initiation and 
IMAGE magnetometer network 1996-11-17

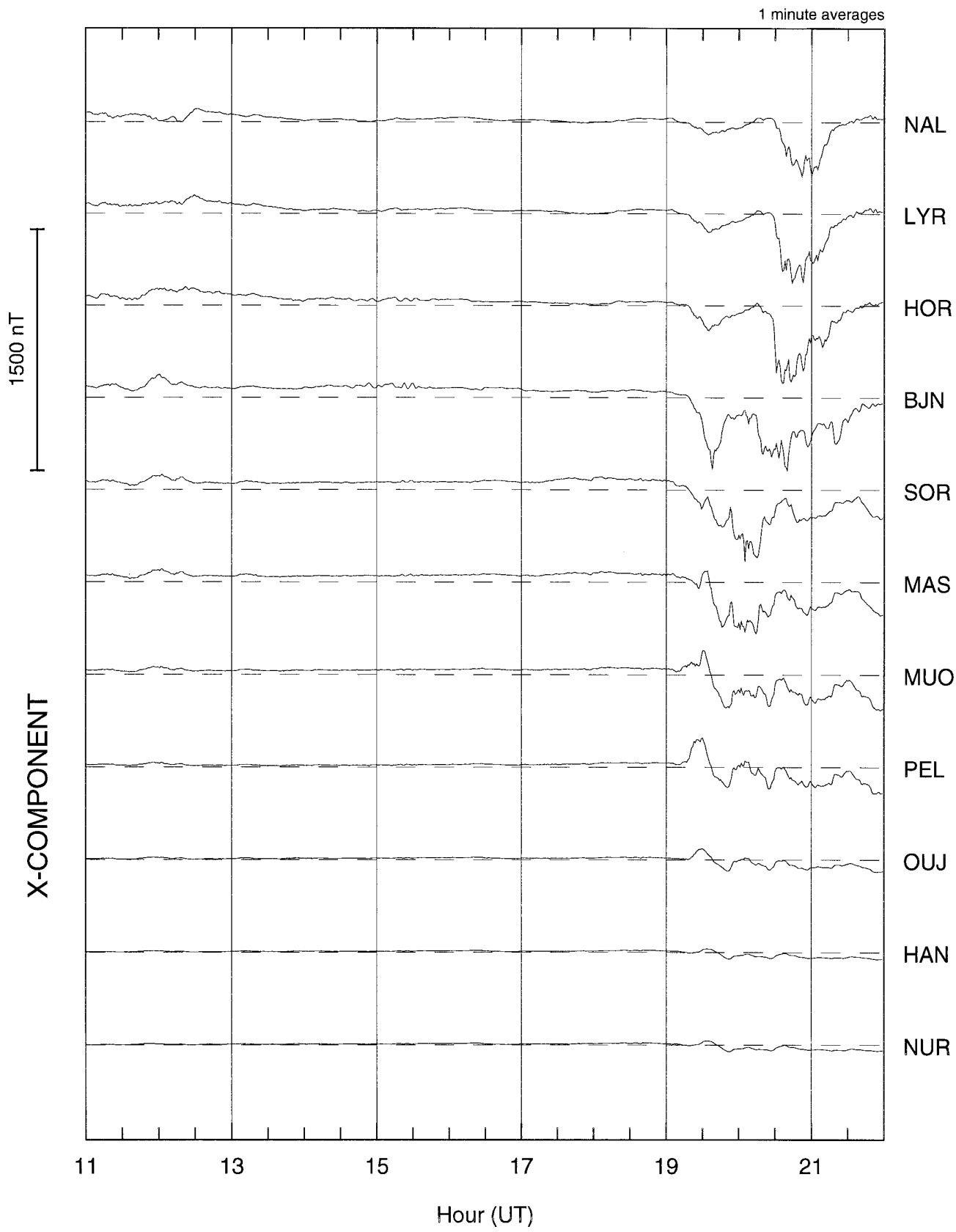

Fig. 1. The X-components of the IMAGE magnetometer network on November 17, 1996

quenching (Karlsson et al., 2000). Note that WIND monitored the solar wind at $\mathrm{X}=19 \mathrm{R} E$ and $\mathrm{Y}=-19$ $\mathrm{R} E$ with a 2.5-3 min signal path delay to the frontal magnetopause. During the afternoon period the IMF variations are at least three times smaller than those during the developed substorm. Between 16 and 17 UT the WIND IMF $B z$ values exhibited weak negative magnitudes of 2-3 nT, which do not seem significant for our study.

Similar to the description made from the geomagnetic data, a stable picture of the auroral activity was observed during the interval 1200-1600 UT by the POLAR UV-Imager (not shown here). In spite of the nearly quiet conditions the auroral oval did not exhibit a theta-aurora configuration.

\section{Observations}

\subsection{Main features of the event}

The main features of the event selected as observed by the Finland CUTLASS radar (beam 12) are exhibited in the multi-panel plot of Fig. 3. Figure 3a-c comprise the irregularity drift velocity, the spectral width and the elevation angle data respectively for the radiated frequency of $12.4 \mathrm{MHz}$. In Fig. 3d-f are the same data but for a radiated frequency of $10 \mathrm{MHz}$. All the data were collected when the Finland CUTLASS radar ran in a fast frequency switching mode.

One can see there the 8-h interval of ribbon echoes, which follow the more equatorward dashed line, which 


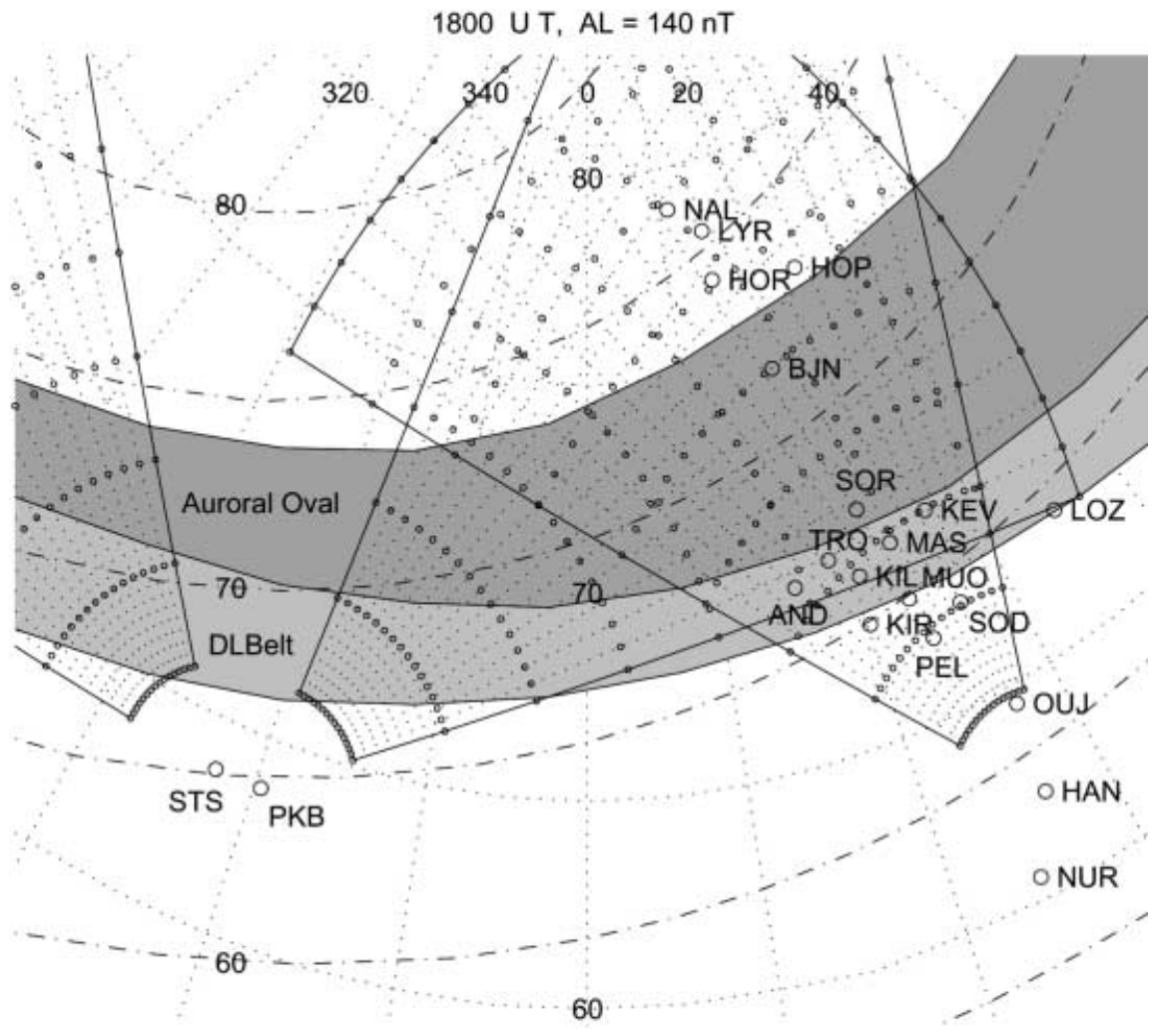

Fig. 2. The collecting area of the Finland (HAN) and Iceland (PKB) CUTLASS radars, where the small open points along the radar beams are the radar beam ground projections through $2.5^{\circ}$; the dash-dotted lines are the CGM-latitudes, the dotted lines give the geographic grid; the heavy lines from top to bottom are the poleward and the equatorward edges of the auroral oval (Feldstein and Starkov, 1967) and the equatorward edge of the diffuse luminosity belt (Starkov, 1994) at 1800 UT and for AL = $140 \mathrm{nT}$ (for more details see Sect. 5) is the model equatorward edge of the diffuse luminosity belt by Starkov (1994). More details on the model are given in Sect. 5. The line runs equatorward through all sub-panels from $68^{\circ}$ to $63^{\circ}$ approximately. These echoes are the main interest of this study. The ribbon echoes are best visible in the two central sub-panels as the widewidth echoes, whose spectral widths are more than 70 $80 \mathrm{~ms}^{-1}$ (those echoes are seen as the yellow-red path along the dashed line). The increased spectral width indicates that these echoes are obviously auroral echoes. Note the logarithmic scale of the central spectral width sub-panels, which we use for better visibility of both the narrow and wide spectra.

During the interval 1200-1930 UT the echoes move $750 \mathrm{~km}$ in latitude with a mean equatorward velocity of $30 \mathrm{~ms}^{-1}$. Such a low velocity suggests that the motion is not of convection nature. Though the event selected looks like an unusual one, it is not a unique case for the Finland CUTLASS radar data, and similar afternoonevening sector echoes can be found during the winter season and near-quiet geomagnetic conditions.

Except for the cited long-lived echo strip, which is our main interest, the left high-latitude part of the width and elevation panels of Fig. 3. include afternoon ground scatter echoes. The ground scatter is eliminated from the top panels of Fig. 3. (which depict velocity) in order for the reader to more easily find the ground scatter echoes in the spectral width and elevation angle panels of Fig. 3. The ground scatter is also distinguishable as randomnly distributed echoes with too high elevation angles at 1200-1530 UT (the red-yellow cloud in the bottom elevation angle panels). The non-realistic eleva- tion angle magnitudes and also the tendency for the elevation angle to grow with distance suggest that these echoes are ground scatter from behind the radar (Milan et al., 1997). It is typically around-noon time when the ground scatter is formed due to the main antenna back lobe(s) and the equatorward $1 \mathrm{~F}$-ground reflection by the dense solar-produced F-layer. The ground scatter echoes can be found also in the evening sector during substorm activity.

The second important feature of the event selected is the substorm-associated echo which is visible in the right side of the figures after 1800 UT. At 1850 UT an early manifestation of the growth-phase development is clearly visible as a fast equatorward motion of the Flayer echoes which started around a magnetic latitude of $70-72^{\circ}$. There are also auroral forms prior to and during the course of the subsequent onsets at 1930 and 1957 UT (Karlsson et al., 2000). The magenta and green lines are the auroral arcs and the equatorward edge of the diffuse luminosity belt, respectively, as they are seen in the Muonio digital all sky camera data.

The third group of echoes which is visible during the entire interval under consideration are the short length and short-lived echoes which have mainly low velocities and increased elevation angles. These randomly distributed echoes with narrow or moderate spectral widths are meteor-induced and/or D-region echoes (Hall et al., 1997). The dispersion of the spectral widths in contrast to their expected narrow width values, we assume, is a result not only of physical phenomena at mesospheric altitudes but also due to the short duration of the main part of the echoes with respect to the radar dwell time. 


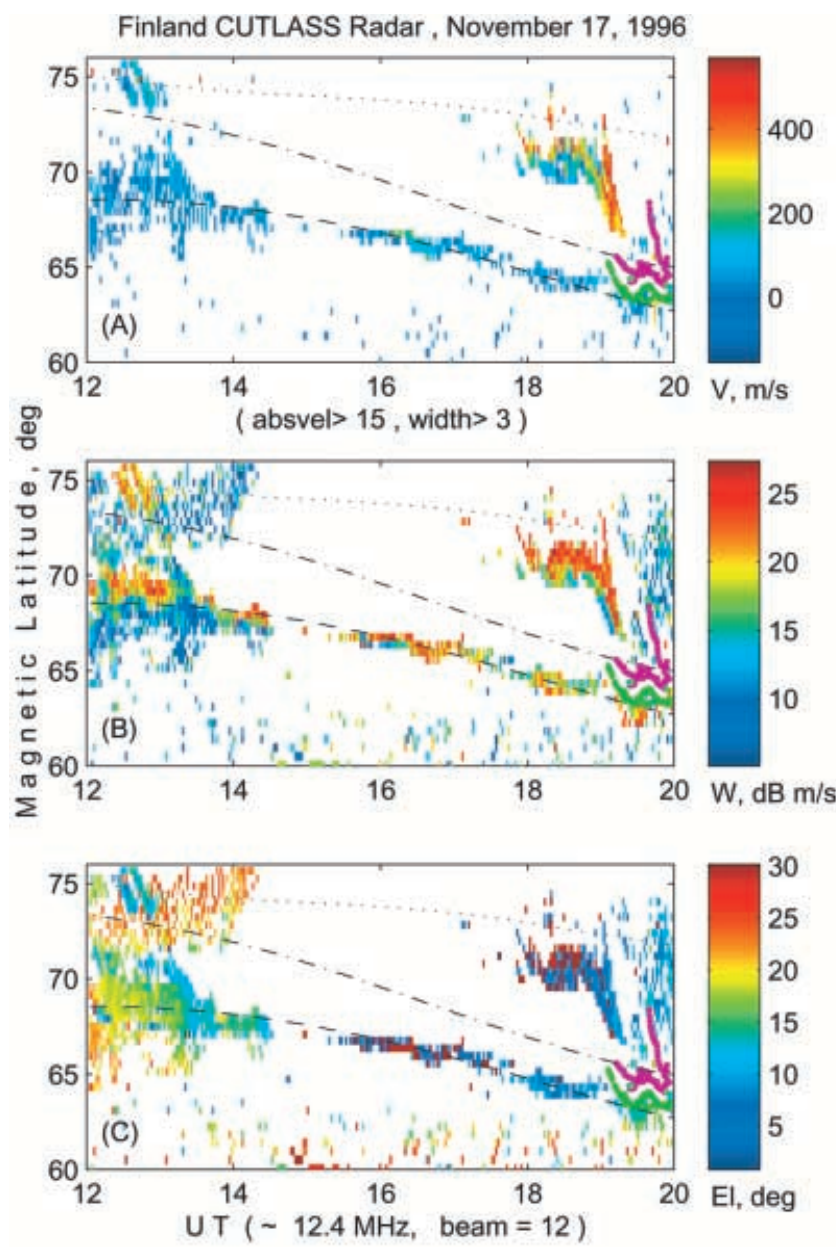

Fig. 3A-F. The Finland CUTLASS radar ribbon echoes, which can be seen as a thin stripe of echoes along the dashed line (the echoes are better visible in the central panels as the yellow-red trace) for two quick-switched radiated frequencies: $\mathbf{A}-\mathbf{C}$ of $12.4 \mathrm{MHz}$ and D-F of $10 \mathrm{MHz}$. The top panels show the Doppler velocities where

\subsection{The ribbon echoes}

The ribbon echoes are mainly the broad (red-yellow) echoes visible in both middle spectral width panels in Fig. 3. They run reasonably well throughout almost $8 \mathrm{~h}$ of the day along the dashed line (see Fig. 3). This line is the equatorward edge of the diffuse luminosity belt derived from a model of the auroral boundaries by Starkov (1994). The dot-dashed line is the location of the most equatorward arc of the auroral oval as described by Feldstein and Starkov (1967). The dotted line is the location of the most poleward arc of the oval. More details of the model will be presented later.

The first feature of the echoes is their reasonably good agreement in position as well as the common motion with the equatorward edge of the diffuse luminosity belt. That explains the too low echo velocities which are, we suggest, the velocity of the auroral oval diurnal rotation as a whole. It is interesting to note that both the echoes and the luminosity edge exhibit common changes in their mean velocity value from the afternoon to evening time. This velocity change is close
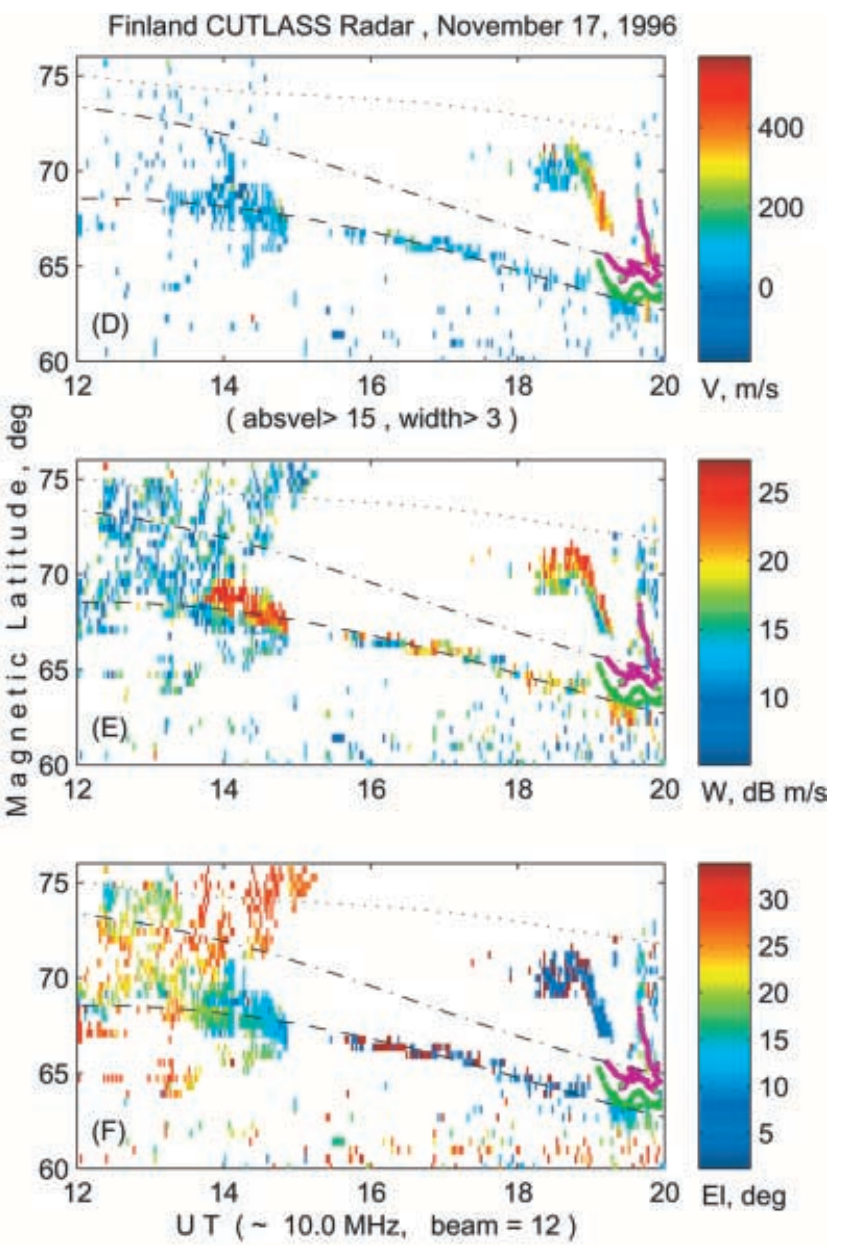

no ground scatter is plotted, the middle panels show the spectral widths in logarithmic scale (NB the limits of the scale are equivalent to linear spectral widths of $3.16 \mathrm{~ms}^{-1}$ and $550 \mathrm{~ms}^{-1}$ ), the bottom panels show the elevation angles. Ground scatter is included in $\mathbf{B}, \mathbf{C}, \mathbf{E}$ and $\mathbf{F}$

to a factor of 2. The second feature is that both the echoes at 12.4 and $10 \mathrm{MHz}$, e.g. at 1500-1900 UT, exhibit a nearly exact colocation with no difference between the data sets. This leads to the general conclusion that a sharp wall of irregularities and/or some specific propagation effect suddenly increases the backscatter volume-cross sections in that very local area.

For further description, we note that the ribbon echoes can be divided into two separate groups using the elevation angle data. Indeed, at 1200-1430 UT we find the broad F-layer 12.4-MHz echoes and at 1330-1450 UT the broad F-layer 10-MHz echoes, which both are located just around the expected position of the equatorward edge of the diffuse luminosity belt. Both echoes are direct $1 / 2 \mathrm{~F}$ echoes. The related $1 \mathrm{~F}$ ground scatter is also observed (Milan et al., 1998). The broad F-layer echoes are slightly larger in their range size than their E-layer counterpart. After 1500 UT both echo sets (related to the diffuse luminosity edge) jump to smaller altitudes, and only Elayer echoes (1/2 E-layer echoes, Milan et al., 1998) are detected, but without the $1 \mathrm{E}$ ground scatter. Their elevation angles (see Fig. 3, bottom panels) now are less 
than $10^{\circ}$ (marked by dark blue colour.) However, also extremely large elevation angles of $30^{\circ}$ and $33^{\circ}$ (marked by dark red, see bottom panels) were detected.

The extremely large elevations arise from elevation angle aliasing due to $2 \pi$ ambiguities in measuring the phase delay and the echo elevation angle noise. The aliasing is typical for low elevation angle values since there is a steeper dependence between elevation angle $(\varepsilon)$ and phase angle $(\phi)$. This conclusion one can easily find from the basic space interferometer ratio between elevation and phase angle, $0<\phi<2 \pi$

$\varepsilon=\arccos (1-m(\phi+\Delta \phi))$

where the coefficient, $m$, depends on the antenna spacing, beam azimuth and also the wavelength. The phase angle noise $(\Delta \phi)$ is mainly the target angle noise modified by the receiver signal-to-noise ratio. During a small $\phi$ and a negative $\Delta \phi$, the phase $\phi$ takes a $2 \pi$ increment to prevent negative values of the second term in Eq. (1) parenthesis. In spite of the angle noise, one can see a tendency that at 1730-1900 UT the 12.4-MHz elevation angles are higher in their values (mainly dark blue) than the $10-\mathrm{MHz}$ echoes. The latter have the mixed dark blue and/or dark red marking. It means that during this time the 12.4echoes are slightly higher in their altitude than the 10$\mathrm{MHz}$ ones. Similar angle noise in similar low elevation angle data is also responsible for the low-to-extremely large elevation angles (dark blue and dark red marking) even for the more distant growth-phase F-layer echoes at 1800-1920 UT. Thus, it is typical for any echoes where low elevation angles are present. During the course of this analysis a comparison can be made of elevation angles for the F-layer growth-phase echoes at 1900 1920 UT (the elevations are $10^{\circ}$ or slightly less) with their counterpart of the wide-width F-layer echoes in the afternoon sector at 14-15 UT (the elevations are 12$15^{\circ}$ ). The comparison shows that the latter echoes are permanently about $100 \mathrm{~km}$ higher in their altitude.

The nearly complete echo blackout at 1450-1530 UT (as well as the change of the echo altitudes) is most probably a consequence of solar illumination. The Elayer echoes occur during late afternoon and evening when the auroral E-layer can have a distinct equatorward leading edge. Appearance of the F-layer echoes is probably independent of the E-layer echoes; however we believe that after 15 UT the F-layer electron densities were not high enough to produce the necessary ray trajectory refraction. The F-layer echoes are seen in the afternoon sector when the solar illumination creates larger F-layer ionisation and simultaneously masks the auroral E-layer leading edge. At noon, the F-layer electron densities are already sufficient to turn the rays so that they become orthogonal to the F-layer magnetic field lines and the $1 / 2$ F-backscatter can be observed.

Due to the moderate, $1100-1300-\mathrm{km}$, F-echo distances, our description of the backscatter suggests that those are of the simplest propagation mode, the direct F-layer backscatter described earlier by Bates (1960, 1961, 1965). Recently Milan et al. (1998) termed this the 1/2 F-layer backscatter. The close location of the F-layer backscatter to the equatorward edge of the diffuse luminosity belt allows us to conclude that the backscatter originates within the area of the F-layer boundary blob (Tsunoda, 1988), which forms the poleward boundary of the main ionospheric trough. The 100 $200 \mathrm{~km}$ range interval of both the 12.4- and 10-MHz Flayer echoes at 1330-1450 UT also support the idea that the F-layer ionisation morphology is a blob-like one.

From simple modelling we can find that before 1430 UT and inside of the blob area, the blob electron density should be not less than $1.7 \cdot 10^{11} \mathrm{~m}^{-3}$. Such an electron density value is already enough to refract the radar beam until it is exactly orthogonal to the magnetic field line at the 300-km F-layer altitude. Between 1430 and 1450 UT (where only the $10-\mathrm{MHz}$ echoes exist) the electron density should be more than $1.1 \cdot 10^{11} \mathrm{~m}^{-3}$. Similar estimates can be made for the time around 15301600 UT where the E-layer echoes are not supported by the F-layer ones. Here the blob electron densities should be already less than $1.1 \cdot 10^{11} \mathrm{~m}^{-3}$. In the interval 1800 1900 UT (when distances of the E-layer echoes fall to about $600 \mathrm{~km}$ ) the absence of the F-layer echoes can be explained if the blob electron densities are less than 1.5$1.7 \cdot 10^{11} \mathrm{~m}^{-3}$. The conclusion is in good agreement with the simultaneous UHF EISCAT data for the same and adjacent regions (Karlsson et al., 2000).

Looking at the E-layer echo spectral widths at 1500 1900 UT, we can see that the majority of the echoes have spectral widths in excess of $100 \mathrm{~ms}^{-1}$. However in addition to these mainly wide spectra there are a noticeable number of very narrow spectra down to values of $10-20 \mathrm{~ms}^{-1}$. No single parameter (except slightly enhanced power for the narrow-width spectra at 1540-1620 UT) can distinguish between the broad and narrow-width E-layer echoes. The narrow-width spectra can have no other physical explanation than being auroral radar backscatter, since the echo distance is too large for them to be meteor scatter, and the echo distance is too small for them to be ground scatter.

During the short intervals of narrow-width spectra, e.g. 1540-1620 UT, there is no reason to suggest that the geophysical parameters, which result in the excitation of the irregularities, are other than local. If it is so, the width of the spectra could be a consequence e.g. of propagation effects, which for specific conditions may modify the azimuth and/or altitude size of the backscatter volume and also granulate the backscatter into the volume unit. Physically it means that the width of the spectra is a result of the large-scale turbulence motion inside the backscatter volume unit and the small-scale backscatter irregularities are only tracers of the motion. Then any shrinkage of the backscatter volume unit to a size, which is less than a characteristic size of the largescale turbulence, will produce some reduction in the width of the backscatter spectrum. A similar conclusion can be obtained when considering the high-resolution equatorial measurements by Farley et al. (1994).

In the direct $1 / 2$ F-layer echoes at 1200-1450 UT (similar to the mentioned E-layer echoes) both broad spectra as well as narrow-width spectra are observed. Particularly noticeable is a group of narrow-width spectra at 1400-1450 UT, which is closely co-located 
with the broad spectrum echoes at their equatorward portion. Here as well no single parameter distinguishes the gradual change of the low width-spectra to their larger width "auroral" values. It appears that both the echo groups have the same nature.

This feature of the auroral backscatter is indirectly supported by a similar effect in the moving growthphase F-layer echoes at 1850-1915 UT. Unusually narrow spectra of $10-20 \mathrm{~ms}^{-1}$ are observed for the echoes with Doppler velocities of $300-400 \mathrm{~ms}^{-1}$ which are apparent at the leading edge of the moving F-layer cloud at $1900-1915$ UT at the latitude of $69-67^{\circ}$. The extremely narrow spectra can be seen in one or two of the nearest range gates only. For larger distances the spectral widths are enhanced and become quickly almost an order of magnitude larger.

The common feature of all narrow-width spectral observations is that they are detected in the nearest or frontal parts of the echo areas. It appears that the length of the ray trajectory, within a dense and randomly irregular media filled by the quasi-isotropic large-scale irregularities, is the specific factor which controls the echo spectral width. Our assumption is that a "pure plasmaphysical unit" of the F-layer backscatter from an isolated volume unit (without a preceding screen of a dense and irregular ionisation) has its inherent spectral width, which is narrower than what is usually observed.

The puzzling feature is the F-layer echoes with narrow spectral width, which are located $100-150 \mathrm{~km}$ equatorward from the model prediction for the position for the equatorward edge of the diffuse luminosity belt. They are clearly visible between 1330-1450 UT. Are they inside of the ionospheric trough? Looking at the echo power plots (not shown here), there is no structure in the power distribution, and the power is nearly the same or even slightly higher in the narrow-spectra area than within the wide-spectra one. However, there are no reasons to expect a stronger power equatorward of the blob poleward wall. Another alternative is whether the latitude of the equatorward edge of the diffuse luminosity belt is a little overestimated in the afternoon sector? There are no immediate answers for these questions, and these echoes warrant further study.

As one can see, the majority of the afternoon F-layer echoes are embedded in a region of ground scatter. The main part of these randomnly distributed ground echoes is the mentioned $1 \mathrm{~F}^{*}$-ground scatter behind the radar (Milan et al., 1997). These are the large-elevation cloudlike echoes in the two bottom panels at 1200-1525 UT (yellow-red marking). The $1 \mathrm{~F}^{*}$-mode of the ground scatter can be confirmed from a comparison of this event with quiet events in the preceding and subsequent days. The growth of the solar zenith angle after 13 UT shifts the 1-hop ground scatter behind the radar to larger distances. Both the 12.4 and $10-\mathrm{MHz} 1 \mathrm{~F}^{*}$-echoes disappear at 1440 and $1525 \mathrm{UT}$, respectively, at the geomagnetic latitude of $76^{\circ}$. The later time is also the demarcation line between the F-layer and E-layer auroral radar backscatter, which arise in the Sunilluminated and non-Sun-illuminated ionosphere, respectively. At $10 \mathrm{MHz}$ the $1 \mathrm{~F}^{*}$-ground scatter disap- pearance occurs later than at $12.4 \mathrm{MHz}$, this is because approximately a 1.5 times smaller electron density is required to support the same propagation mode.

\section{Model of the auroral boundaries}

Starkov (1994) suggested an AL-dependent model for the auroral boundaries. The model is based on optical observations by Feldstein and Starkov (1967) and satellite measurements of soft auroral electron precipitation by Gussenhoven et al. (1981, 1983). It was suggested that the equatorward edge of the diffuse luminosity belt is matched to a sharp electron precipitation cutoff with a threshold in particle precipitation of about $107 \mathrm{~cm}^{-2} \mathrm{~s}^{-1} \mathrm{sr}^{-1}$. This is consistent with a mean particle energy of $600 \mathrm{eV}$ and a total energy flux of $10^{-2} \mathrm{erg} \mathrm{cm}^{-2} \mathrm{~s}^{-1} \mathrm{sr}^{-1}$ (Gussenhoven et al., 1981). Using a photometer network, Slater et al. (1980) confirmed the colocation of a sharp precipitation cutoff in the satellite data with the location of the equatorward edge of the diffuse luminosity belt. For more information on features of the diffuse luminosity belt see, e.g Anger and Lui (1973), Lui et al. (1973), Galperin et al. (1977), Georgio et al. (1978), Ivanov et al. (1993), Pudovkin et al. (1995), Liou et al. (1997) and references therein. A similar model was earlier suggested by Holzworth and Meng (1975). They organised the auroral boundaries according to Q-indices, which are no longer widely used. Furthermore, the authors did not define the boundary of the diffuse luminosity belt.

The location of the auroral boundaries for $\mathrm{AL}=-140 \mathrm{nT}$ is plotted in all panels of Fig. 3 as a function of geomagnetic latitude and universal time. The equatorward dashed line is the equatorward edge of the diffuse luminosity belt. The dashed-dotted and dotted lines are the locations of the most equatorward and most poleward auroral arc(s). Thus the two last lines define the boundaries of the auroral oval for the discrete luminosity (Feldstein and Starkov, 1967).

In our model application we met an uncertainty in the AL-value selection. For the main time interval of 1200-1930 UT the IMAGE AL-index was $80-100 \mathrm{nT}$, for the interval of 0000-1200 UT, 200-250 nT, for the interval of 1930-2400 UT it became 500-550 nT. For optimal agreement with the wide spectra ribbon echoes along the edge of diffuse luminosity (dashed line), we chose AL $140 \mathrm{nT}$.

Figure 3 clearly shows that the echoes follow the equatorward edge of the diffuse luminosity belt reasonably well, gradually changing their position in accordance with the auroral oval diurnal rotation. At least two facts can support our proposition that the echo and luminosity edge coincidence has a physical explanation. The first is that the interval during which the two boundaries follow each other is very long. The second fact is the reasonably good gradual merging of both the ribbon echoes and Starkov's (1994) boundaries in the subsequent substorm development. This is observed after 1910 UT in the Muonio all sky camera data. Note that the first appearance of the faint auroral arc 
(magenta line) starts at a point nearly coincident with the model equatorward auroral oval boundary. In contrast, the visible equatorward edge of the diffuse luminosity is detected deep inside the model diffuse luminosity belt (the edge of the belt is the green line). We assume it is probably an equatorward moving luminosity structure, which is a manifestation of the substorm growth-phase development. Within $10 \mathrm{~min}$ from its appearance (but before the onset) the visible luminosity structure nearly merges with its model counterpart.

We suggest that the event presented here is an example of a prolonged time period when an auroral radar can monitor the equatorward edge of the visible or sub-visible diffuse luminosity belt, i.e. the inner boundary of the electron plasma sheet in nearly quiet geomagnetic conditions. Such a possibility is very important and can make significant applications in the study of auroral backscatter. This possibility led us to collect and analyse related and accessible information, which can support or disprove the idea. Also, it is important to investigate the exact physical condition, which gives rise to the formation of such auroral radar backscatter.

\section{Electron densities in the diffuse luminosity belt}

During the evening of November 17, 1996, the European Incoherent Scatter Facility, EISCAT (Folkestad et al., 1983) was operated in the UHF Common Programme 1 with the antenna pointing along the magnetic field line. As reported by Karlsson et al. (2000), between 1850 and 1900 UT the UHF EISCAT radar detected enhanced electron densities near the altitude of about $120 \mathrm{~km}$, when a faint southward drifting growth-phase arc enters the UHF EISCAT beam. Since the geomagnetic latitude of the UHF EISCAT antenna beam at the E-layer altitude is around $66^{\circ}$, this description agrees well with the auroral boundary model by Starkov (1994) discussed already. However, the UHF EISCAT radar also detected enhanced E-layer ionisation which can be seen well between 1800 and 1825 UT. During this time the UHF EISCAT antenna beam was $1.0-1.5^{\circ}$ equatorward of the auroral oval calculated by Feldstein and Starkov (1967) being deep inside the diffuse luminosity belt. The electron densities from the UHF EISCAT data are around $0.6-0.7 \cdot 10^{11} \mathrm{~m}^{-3}$. The drop of the electron densities between 1825 and 1850 UT does not contradict our description, because this region is known as the diffuse luminosity gap (Senior et al., 1982).

EISCAT, at 1800-1900 UT when its antenna beam covered the diffuse luminosity belt, did not detect any Flayer ionisation exceeding $0.5 \cdot 10^{11} \mathrm{~m}^{-3}$. This agrees with our conclusions in Sect. 4 and explains the absence of the F-layer backscatter during the evening hours.

\section{Formation of a latitudinally limited backscatter pattern}

It is widely accepted that ionospheric refraction is a key factor for the HF-band, which makes it possible to observe F- (also E-)-layer field-aligned irregularities as tracers of the plasma bulk motion (Greenwald et al., 1983, 1985). However, there are caveats to this interpretation. Indeed, the backscatter probability is a convolution of the occurrence of ionospheric irregularities and the ability of the radar to illuminate the ionosphere with the ray trajectories, which run orthogonal to the magnetic field line. The last factor, as will be discussed, is not a simple one.

For example, in the main collecting area of the Finland CUTLASS radar, the rectilinear ray trajectories meet the E-layer magnetic field lines nearly exactly orthogonal. Then the ionospheric refraction becomes a negative factor because the best points for the highest radar sensitivity (to the field-aligned irregularities) in its viewing area are those where no refraction occurs. There are at least two regions where no ionospheric refraction occurs: the areas where no ionisation (i.e. no backscatter) occurs and the areas where the ray trajectories run orthogonal to the electron density isolines. The last point is a specific characteristic of the layer leading edges, e.g. with the anti- and/or-radarward gradients, being better observed than the surrounding background.

To illustrate this phenomenon in a quantitative but simplified manner, we assume that in the area of interest the field-aligned irregularities exist everywhere. Secondly we suggest that in the meridional plane the E-layer is half-infinite with electron density values around $0.7 \cdot 10^{11} \mathrm{~m}^{-3}$ (as measured by EISCAT in the interval 1800-1830 UT) and with its equatorward leading edge oriented in a similar manner to the equatorward edge of the diffuse luminosity belt. For an arbitrary E-layer meridional altitude profile given in bottom right panel of Fig. 4, the aspect angle for a radar ray trajectory becomes a sum of its "non-disturbed", IGRF-based, rectilinear value and an increment due to the ionospheric refraction. Note, the refraction itself is the function of the incident angle of a radar ray trajectory to the local electron density isoline. The calculated distribution of aspect angles inside the model E-layer is the base upon which to define the relative local backscatter volume cross section magnitudes. The volume cross sections, we suggest, are a product of the second power of the local electron density and the backscatter aspect angle attenuation (see e.g. Uspensky and Williams, 1988).

The heavy lines in the left panels of Fig. 4 illustrate the $12.4-\mathrm{MHz}$ backscatter volume cross-section distribution around the E-layer leading edge. The E-layer profile at the bottom right panel has an external isoline of $0.02 \cdot 10^{11} \mathrm{~m}^{-3}$. The subsequent isolines have an increment of $0.1 \cdot 10^{11} \mathrm{~m}^{-3}$. The tongue-like area, which is visible in each LHS panel (except the bottom one, which comprises rectilinear aspect angles), is the area of strongest signal. The internal tongue-like isoline in the LHS panel for beam 8 is at $-6 \mathrm{~dB}$ with respect to the local echo maximum. The other power isolines occur at steps of $-20 \mathrm{~dB}$. The other left hand figures do not include any normalisation, but they were adjusted with respect to the beam 8 picture.

The dashed lines which run through the tongue centre are the lines where the refraction-modified aspect 

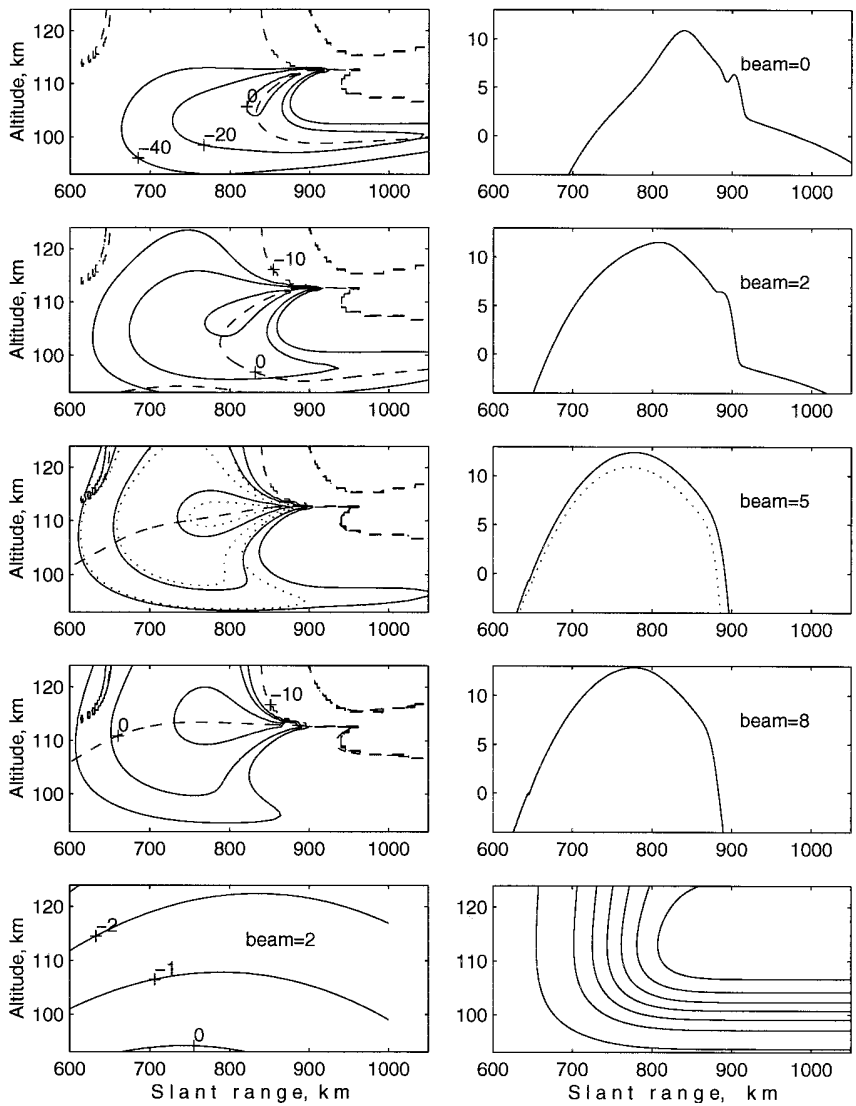

Fig. 4. The left panels (except the bottom) show the 12.4-MHz model backscatter volume cross section distribution for the Finland CUTLASS radar in the area of the auroral E-layer leading edge. The dotted lines in the left and right middle panels are for the $10-\mathrm{MHz}$ echoes, the dashed lines are their refraction-modified aspect angle isolines. The left bottom panel shows the rectilinear aspect angles for the antenna beam 2. The right panels show the height-integrated meridional power profiles as seen by the radar. The right bottom profile is the model E-layer profile, where the external line is $0.02 \cdot 10^{11}$, the next ones are higher densities with steps of $0.1 \cdot 10^{11} \mathrm{~m}^{-3}$; the highest density is $0.71 \cdot 10^{11} \mathrm{~m}^{-3}$

angle is zero. The magnitude of the aspect angle modification due to the refraction can be estimated by a comparison of the $2 \mathrm{nd}$ beam rectilinear aspect angles given in the left bottom panel with the refractionmodified ones for the same beam given in the second left panel. One can see that refraction pushes up the zero aspect angles from the very bottom and distorts them at the central E-layer altitudes. In the second left panel, in the area to the left of the modified zero aspect angle isoline the aspect angles are negative. To the right of the zero-line the aspect angles are positive.

When the rectilinear aspect angles become more negative e.g. for beam 0 (the most westward beam), then the refraction-modified aspect angles tilt the backscatter tongue to lower altitudes and larger distances as shown in the left top panel. For the pointing directions with beam numbers more than 5 or 6 the rectilinear aspect angles become zero even at $110-\mathrm{km}$ altitude. As a result, the tongue-like area of the largest cross section moves also to higher altitudes and the dashed line of exact orthogonality runs nearly horizontally.
For direct comparison, in the central left panel (beam 5) one can find also the $10-\mathrm{MHz}$ volume cross sections, which are shown by the dotted lines. Due to stronger refraction the $10-\mathrm{MHz}$ cross sections are more limited and slightly lower in altitude than the $12.4-\mathrm{MHz}$ ones. This difference in altitude is a function of the E-layer electron density altitude gradient. We have not attempted to find a stronger gradient influence however, we guess, for a specific value the difference in altitude between 12.4- and $10-\mathrm{MHz}$ echoes can be greater. It seems the effect at least does not contradict the similar experimental tendency, which can be seen at 1730 1900 UT for the 12.4-MHz SEEL-echoes to be slightly higher in altitude than the $10-\mathrm{MHz}$ ones (see Sect. 4).

In our modelling (Fig. 4), we built the altitude-range distribution of relative backscatter volume cross sections (VCS), where the structure is a function of the sharp field aligned anisotropy of the auroral radar backscatter. This altitude-range VCS distribution cannot be resolved experimentally by the CUTLASS radar, since the elevation angle pattern is too wide, but the interferometer data comprise the mean power-weighted wave arrival angle only. The right panels of Fig. 4 show the calculated height-integrated meridional power profiles as a function of distance. It is just the same manner in which the radar observes the measured range-power quantities.

Two features can be found in the power profiles. The power decreases as a function of the antenna beam number decrease and a matched gradual profile shift to larger distances $(60-70 \mathrm{~km})$. Both effects can be considered to be a function of the rectilinear off-orthogonal (aspect) angle, e.g. at $110-\mathrm{km}$ altitude. A third feature is the range spread of the power profile itself, which is around two range gates at $-3 \mathrm{~dB}$ level and around 3 range gates at the $-6 \mathrm{~dB}$ level. Both values are close to the ribbon echo range spread measured. The range spread and the range shift (as a function of beam number decrease) is a function of the electron density gradient in the leading edge of the E-layer. A smaller gradient will result in a larger range spread and a larger shift in range.

It is important to note that the features mentioned in the modelling can also be found in the experimental data. The top two panels of Fig. 5 show the experimental dependence of the mean power (open circles) and the two bottom panels show the mean distance (open circles) for the 12.4- and $10-\mathrm{MHz}$ ribbon echoes as a function of the beam number. In spite of the limited statistics for low beam numbers, the mutual agreement between the model and the experimental data seems reasonable, although the model power decrease is less pronounced. Probably the latter is due to the exponential aspect angle dependence used in the modelling. The exponential function has an aspect angle attenuation softer than $10 \mathrm{~dB} / \mathrm{deg}$ (Fejer and Kelley, 1980) if the aspect angle in its absolute value is equal to or less than $1^{\circ}$. Note, that the mean distance dependence includes two effects, which act in a similar manner. One is the aspect angle-controlled range-shift of the power profile found in our modelling and the other is the gradual 

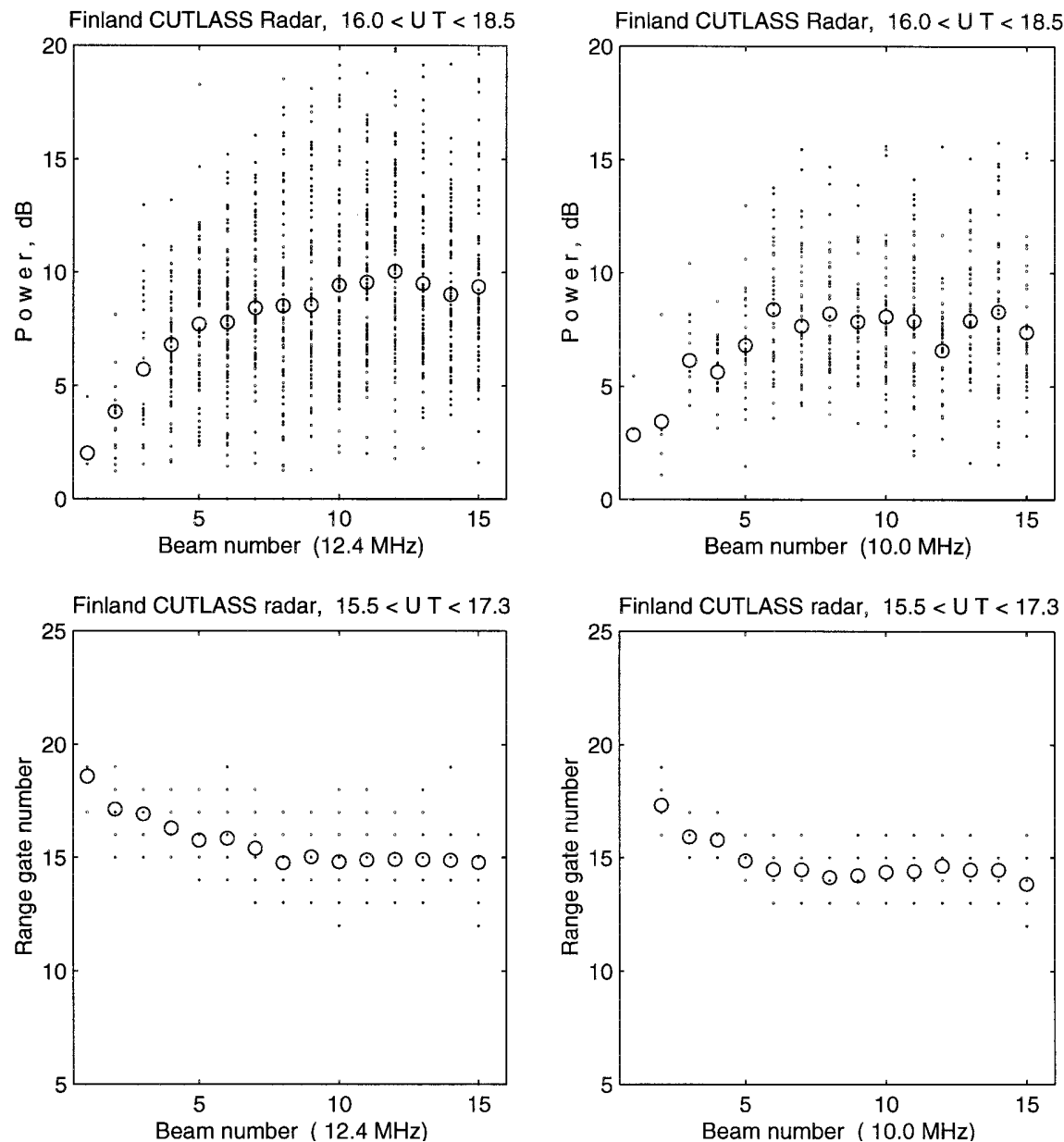

Fig. 5. The top two panels show the backscatter E-layer echo power statistics as a function of the Finland CUTLASS radar beam number for two radiated frequencies of 12.4 and $10 \mathrm{MHz}$. Open circles show mean power values; the two bottom panels show the ribbon echo range gates. The open circles are again mean values; for all data the echo spectral width $>80 \mathrm{~ms}^{-1}$ growth of distances between the radar and the equatorward edge of the diffuse luminosity belt seen in Fig. 2.

As a summary, the model and experimental data suggest that the limited meridional size of the Finland CUTLASS echoes is a direct product of the nearly total rectilinear orthogonality of the Finland CUTLASS radar site for the E-layer altitudes. As a result, the moderate and intense echo can be seen with a larger priority in the vicinity of the E-layer leading edge. From the point of view of the physics the leading edge acts like an optical defocusing lens. The lens diverges a bunch of ray trajectories so that only a few rays can meet the magnetic field line exactly orthogonal.

At larger distances (behind the layer edge), where the incident angle between the ray trajectory and nearly horizontal electron density isoline decreases down to values of $10-15^{\circ}$, the ionospheric refracton grows progressively. As a result, the refraction becomes the dominant factor, which in any case bends the rays away from the initially orthogonal geometry. It crucially eliminates the HF backscatter power for a wide range of electron densities down to $(0.50 .6) \cdot 10^{11} \mathrm{~m}^{-3}$. The latter is close to the background electron density for the nearly quiet geomagnetic conditions (Milan et al., 1997). An ideal case of a planar and homogenous E-layer, does not contradict the fact that the small-scale field-aligned irregularities can exist everywhere inside such a "non-visible" E-layer which could cover all the radar collection area.
However, we note the existence of a natural limit to observe such size- limited echoes. The mentioned echo features can be clearly seen if the straight-line aspect angle is close to zero, i.e. the distances for the Finland CUTLASS radar cannot be less than 500-600 km. In the afternoon and evening sector this can happen if a substorm is weak with the equatorward edge of the diffuse luminosity belt located at geomagnetic latitudes higher than $64.5-65.0^{\circ}$.

\section{Physical interpretation for the ribbon echoes}

In the framework of this study we considered the longlived F- and E-layer echoes which cover the equatorward edge of the diffuse luminosity belt. Since such luminosity is sub-visual (both in the afternoon Sunilluminated and in the evening non-illuminated ionosphere) it seems logical to associate the ribbon echoes with the SEEL-echoes, i.e. the echoes from the subvisual equatorward edge of the diffuse luminosity belt. This is important, as there is no other ground-based means to map and monitor the dynamics of the lowdensity equatorward subvisual edge of the diffuse luminosity belt. Using radars, this boundary can be observed even during intervals of solar illumination. The conditions under which such monitoring could be most effective are open for future studies. 
The term SEEL-echoes does not contradict the fact that for part of the time the luminosity edge can be visible by optical means. This happened e.g. after 1910 UT, when the moving structure in the diffuse luminosity belt (Fig. 3, green line) was detected by the Finland Muonio digital all sky camera. After 1910 UT (Fig. 3), the Elayer echoes were shifted equatorward to lower latitudes. We assume weaker luminosity (and smaller electron densities) were present equatorward of the visible moving diffuse luminosity structure (the heavy green line).

Note the absence of echoes between the visible luminosity edge and auroral arc during the interval of 1910-2000 UT (the interval between the heavy green and the heavy magenta lines). It is an example of where the horizontal ionisation bends or even reflects the ray trajectories obscuring the backscatter. As a confirmation, the E-layer ground reflection at 1930-2000 UT, which originates in the area between the luminosity edge and the auroral arc, can be seen at geomagnetic latitudes of $68-72^{\circ}$.

The SEEL-echoes allow the visualisation of the ionospheric footprint of the inner boundary of the electron plasma sheet during nearly quiet geomagnetic conditions. It opens more possibilities to gain physical insights into magnetosphere-ionosphere coupling as well as magnetospheric physics. It is a pity that the Finland CUTLASS radar is not suitable to monitor stronger substorms, when we expect magnetospheric phenomena at the inner edge of the plasma sheet such as luminosity edge wave undulations or ripples (Lui et al., 1982). For such a possibility, a facility similar to the Finland CUTLASS radar should be installed at least a few degrees lower in latitude.

\section{Discussion}

Villain et al. (1987) noted earlier that refraction and density gradients can create conditions during which only a few rays can achieve perpendicularity near the centre of the electrojet, where little refraction occurs. However, they suggested that the same order of backscatter can occur nearby after ray bending also. Our observations are from a situation when a few rays are at the centre of the electrojet and they define the tongue-like E-layer leading edge backscatter. No other nearby points exist, where similar echo power could be picked up. This is characteristic of the Finland CUTLASS radar to monitor the echoes at moderate or large E-layer distances. The main points which support and illustrate the specific features of how the Finland CUTLASS radar can detect and monitor the equatorward edge of the diffuse luminosity belt are:

a. In the example presented here both the luminosity edge found from the model by Starkov (1994) and the narrow strip of the afternoon F-layer and the evening E-layer echoes co-exist and move together during about 8 hours.

b. Our modelling confirms the specific location and properties of the Finland CUTLASS radar echoes with the increased cross sections. They are a result of the zero E-layer rectilinear aspect angles. The echoes can be found in a restricted area around the leading edge of that E-layer filled by the decameter fieldaligned irregularities. In the leading edge only the radar ray trajectories can run nearly normally to the electron density isolines, these remain the rays to be undisturbed by the refraction.

c. Our modelling predicts that if the E-layer is nearly horizontal and the electron density is more than $(0.5-0.6) \cdot 10^{11} \mathrm{~m}^{-3}$, strong over-refraction obscures the E-layer backscatter nearly everywhere with one exception when the E-layer can be seen from the radar site at very short distances (e.g. less than 300 $400 \mathrm{~km}$ ). The experimental data support this conclusion.

d. We suggest that the F-layer backscatter in the vicinity of the equatorward edge of the diffuse luminosity belt is due to the unique relationship of the F-layer boundary blob to the equatorward auroral boundary (Tsunoda, 1988).

e. We have found supporting experimental facts that the SEEL-echoes have the features predicted by the modeling for the volume cross section distribution (Fig. 4): a minor regular echo shift to larger distances, which can be found for the western CCW Finland CUTLASS radar antenna beams (where the aspect angles gradually move away from orthogonality); a simultaneous matching drop of the backscatter amplitudes and a tendency for echo spectral width to become narrower with the echo altitude decrease; and a tendency for the 12.4-MHz echoes (e.g. at 1730 1900 UT) to be slightly higher in elevation angles (altitudes) than their $10-\mathrm{MHz}$ counterpart.

f. The SEEL-echoes and the model auroral boundaries agree with the position of the auroral arc and the equatorward edge of the diffuse luminosity during the course of the subsequent growth-phase and substorm development.

g. For two radiated frequencies 12.4 and $10 \mathrm{MHz}$, the echo positions are the same, i.e. the echo position is not frequency dependent, in contrast to what could be expected for a horizontal and homogenous ionosphere (Uspensky et al., 1994).

An important point to understand in the physical conditions for the irregularity excitation is the electric field in the SEEL-echo area during the nearly quiet geophysical conditions. One source of the information on the electric field is the azimuth Doppler velocity scans available for the Finland CUTLASS radar. In accordance with Villain et al. (1987), the azimuth velocity variations can define relatively low ionospheric electric fields even for the sub-critical gradient drift modes, which we can expect for our case.

The Finland radar azimuth velocity scans at 1500 1748 UT and 1800-1900 UT show that the SEELechoes are located inside the westward electron flow, i.e. inside of the afternoon-evening eastward electrojet. At 1800-1900 UT the azimuth of the Doppler velocity reversal exhibit that the electrojet flows along the 
equatorward edge of the model diffuse luminosity belt (Starkov, 1994). For the time the irregularity drift velocity for echoes with spectral widths $>80 \mathrm{~ms}^{-1}$ was approximately $300 \mathrm{~ms}^{-1}$. The velocity dispersion was of the order of $100 \mathrm{~ms}^{-1}$. At $1500-1748$ UT the velocity reversal shows that the electrojet flows roughly along $L$ shells and the drift velocity was $200 \mathrm{~ms}^{-1}$. That is obviously not enough to excite the two-stream irregularities. Thus, the irregularities have the drift gradient nature (Fejer and Kelley, 1980), which play an important role in forming decametric irregularities. In the evening the bottomside E-region gradients together with the westward plasma flow are favourable for the growth of gradient-drift modes.

Another source of information on the electric field in the SEEL-echo area can be Iceland CUTLASS radar data if the auroral radar backscatter collected from directions nearly along the main electron flow. Our inspection shows that at 1800-1850 UT velocities of $300 \mathrm{~ms}^{-1}$ were typically present. They were smaller toward higher latitudes than the SEEL echo projection approximately, similar as described by Unwin and Cummack (1980) for the drift velocity spikes. These estimates are reasonably confirmed by the independent velocity estimates for the Finland azimuth scan data. For an earlier time, e.g. 1650-1800 UT, drift velocities were $100-200 \mathrm{~ms}^{-1}$ showing values that were too spread.

One other point of interest is how the Iceland CUTLASS radar "sees" the auroral backscatter during the time of the Finland radar SEEL-echoes. We used the 0th-3rd Iceland radar antenna beams, which were oriented similarly with respect to the auroral oval (only oppositely directed) to the Finland radar antenna beams. In spite of the zero aspect angle conditions we did not find the SEEL-like echoes because the Iceland CUTLASS radar is at $6^{\circ}$ higher in geomagnetic latitude than that in Finland. As a result, the equatorward edge of the diffuse luminosity belt there was too close to the radar, taking the distances where the rectilinear aspect angles were too far from orthogonality. However, we saw intermittent E-layer echoes which originated deeper inside the luminosity belt. Due to the "almost-zero" aspect angle condition, local ionospheric structures, e.g. the gradients or tilts, can occasionally decrease the refraction. These created short-term conditions suitable for the quasi-orthogonal backscatter. These intermittent E-layer echoes were seen between 1530 and 1830 UT, i.e. at the same time, as the Finland CUTLASS radar observed the SEEL-echoes.

The joint analysis of the Finland and Iceland CUTLASS data, (e.g. at 1800-1850 UT) reveals that the backscatter powers in the SEEL areas are rather close to each other. If one suggests that the ionospheric conditions in two separated backscatter volumes are similar, then the backscatter flow angle dependence is nearly isotropic.

It is of particular interest to search for similar features in the high-latitude F- and E-layer dynamics by using incoherent scatter data. The main features of the high-latitude ionosphere, which are suitable for a comparison with our data, were summarised by Tsunoda (1998 see also Rino et al., 1983; Weber et al., 1985). For the late afternoon and evening sector we find the following: (a) the dense solar-produced F-layer $\left((10-12) \cdot 10^{11} \mathrm{~m}^{-3}\right)$, the ionospheric trough $\left(10^{11} \mathrm{~m}^{-3}\right)$, the F-layer boundary blob $\left((3-4) \cdot 10^{11} \mathrm{~m}^{-3}\right)$, and the underlying auroral E-layer $\left(1.5 \cdot 10^{11} \mathrm{~m}^{-3}\right)$ are co-located and are typical of the afternoon sector; (b) the location of the E-layer measured by the incoherent scatter radar map to the region of the $1-20 \mathrm{keV}$ electron precipitation and $4278 \mathrm{~nm}$ optical auroral features (Weber et al., 1985); (c) in the afternoon period the field-aligned projection of the leading equatorward edge of the E-layer can be located $1-2^{\circ}$ lower in latitude than the ionospheric trough projection (as well as the poleward boundary blob wall); the electron densities in the leading E-layer edge are $>0.5 \cdot 10^{11} \mathrm{~m}^{-3}$ approximately; (d) at later evening times, the F-layer boundary blob electron densities gradually decrease, but the trough and the boundary blob overtakes the equatorward edge of the E-layer in their common equatorward drift.

The features (a)-(d) support our conclusions of the HF radar SEEL-signatures: i.e. (aa) the leading edge of the E-layer and the equatorward edge of the diffuse luminosity belt are physically the same: (bb) the F-layer boundary blob echoes can be observed until early evening time when the blob electron density becomes less than the observational refraction-dependent threshold for the HF 1/2 F-auroral backscatter; the $10-\mathrm{MHz}$ $1 / 2$ F-echoes can be seen longer in time than their 12.4$\mathrm{MHz} 1 / 2 \mathrm{~F}$-counterpart: (cc) if we consider the broad Flayer echoes as the boundary blob echoes then their position deeper than the E-layer echoes in the diffuse luminosity belt is consistent with point (c) above: and (dd) the E-layer electron densities observed are consistent with our model conclusions.

On the other hand, the question regarding the lowlatitude position of the narrow-width afternoon F-layer echoes (i.e. lower in their latitude than the model diffuse luminosity edge) is still open. Their better visible part can be seen at 1330-1450 UT. Maybe the F-layer echoes could be caused by the anti-sunward transport of the solar-produced F- layer ionisation from the cusp region into the night-time auroral zone (Weber et al., 1985). Note that the effects observed occur $4 \mathrm{~h}$ after local magnetic noon. The answer to this question is also open.

\section{Conclusion}

From the data analysis and modelling we conclude the following:

1. The prolonged motion of the size-limited auroral Fand E-echoes follows the equatorward auroral boundary of the diffuse precipitation and luminosity, i.e. along the ionospheric footprint of the inner boundary of the electron plasma sheet during nearly quiet geomagnetic conditions. This analysis reveals the possibility for the Finland CUTLASS radar to be used as a tracer of the SEEL, the subvisual equator- 
ward edge of the diffuse luminosity belt during quiet geomagnetic conditions.

2. The position of the SEEL-echoes as well as the model auroral boundaries by Starkov (1994) are matched with subsequent growth-phase arc and diffuse luminosity signatures of the first substorm onset at 1930 UT.

3. The first approach was made for the physical description how, why and where the Finland CUTLASS radar sees the size-limited E-layer echoes. Those are the frontal positive (and probably negative) gradients of electron density, which act similarly to a defocusing (or focusing) lense. For at least a few rays in the vicinity of the layer altitude centre, the refraction is too small to turn the rays away from the already existing "right" orthogonal geometry. Those rays define the intense size-limited E-layer echoes; the F-layer echoes originate slightly inside of the boundary blob where the refraction can already compensate the $10-15^{\circ}$ straight-line off-orthogonality.

4. The F- and E-layer SEEL-echoes are a product of increased electron drifts of $200-350 \mathrm{~ms}^{-1}$ in the vicinity of the poleward wall of the main ionospheric trough. The existence of these echoes shows the drifts are large enough to support the gradient-drift excitation of decameter field-aligned irregularities. In the E-layer the irregularities have nearly isotropic flowangle dependence.

5. Two separate time intervals for the F-layer and Elayer SEEL-echoes are a consequence of the solar control on the ionospheric ionisation when during the afternoon the E-layer leading edge is masked by the solar-produced ionisation (it obscures the E-layer echoes), and at the same time the F-layer boundary blob ionisation is enough to turn the ray trajectories for the intense backscatter. The opposite case is in the evening when the boundary blob is less dense (not sufficient to form the F-layer echoes), but the auroral E-layer has a distinct leading edge which forms the SEEL-echoes.

6. The azimuth-power and azimuth-range dependences found in the SEEL-echo modeling are confirmed in the observational data.

7. The incoherent scatter data of the auroral ionisation structure and behaviour, e.g. in the ionospheric trough, in the F-layer boundary blob, and in the auroral E-layer (Rino et al., 1983; Weber et al., 1985; Tsunoda, 1988), support our conclusions on the Fand E-layer echo dynamics derived from the Finland CUTLASS radar data.

8. The predominance of the narrow spectral auroral E and F-layer echoes in frontal parts of the echo areas suggests that the length of the ray trajectory path into a dense and large-scale irregular medium is the factor, which controls the echo spectral width.

Acknowledgements. The authors thank L.A. Frank, University of Iowa, for providing the Polar Visible Imaging data. We also thank R.P. Lepping for the WIND plasma data. The CUTLASS radar is supported by the University of Leicester, the Finnish Meteorological Institute and the Swedish Institute of Space Physics. Work at the Polar Geophysical Institute was performed under RFFR grant 65103.

Topical editor M. Lester thanks S. Milan and P.L. Dyson for their help in evaluating this paper.

\section{References}

Anger, C. D., and A. T. Y. Lui, A global view of the polar region on 18 December 1971, Planet Space Sci., 21, 873-878, 1973.

Bagaryatsky, B. A., Auroral radar echoes, Uspehi Phys. Nauk, 63, 197-241 (in Russian), 1961.

Bates, H. F., Direct HF backscatter from the F region, J. Geophys. Res., 65, 1993-2002, 1960.

Bates, H. F., The slant Es echo - a high-frequency auroral echo, J. Geophys. Res., 66, 447-454, 1961.

Bates, H. F., Some effects of dense Es clouds on high-latitude HF backscatter observation, J. Geophys. Res., 70, 5895-5905, 1965.

Bates, H. F., A. E. Belon, G. J. Romick, and W. J. Stringer, Continuous observation of the auroral belt by means of radio, Nature, 207, 1081-1082, 1965.

Bates, H. F., A. E. Belon, G. J. Romick, and W. J. Stringer, On the correlation of optical and radio auroras, J. Atmos. Terr. Phys., 28, 439-446, 1966.

Bates, H. F., R. D. Sharp, A. E. Belon, and J. S. Boyd, Spatial relationship between HF radar aurora, optical aurora and electron precipitation, Planet Space Sci., 17, 83-95, 1969.

de la Beaujadiere, O., R. Vondrak, and M. Baron, Radar observations of electric fields and currents associated with auroral arcs, J. Geophys. Res., 82, 5051-5062, 1977.

Ecklund, W. L., and R. S. Unwin, Magnetically conjugate observations of the radio aurora, Nature, 232, 54-56, 1971.

Egeland, A., Scattering of radio waves from auroral ionisation, in: Cosmical geophysics, Eds. Egeland, A., O. Holter, and A. Omholt, Scandinavian University Books, Munksgaard, Copenhagen, 311-325, 1973.

Farley, D. T., W. E. Swartz, D. L. Hysell, and C. Ronchi, Highresolution radar observations of day-time kilometer wave structure in the equatorial electrojet, J. Geophys. Res, 99, 299307, 1994.

Fejer, B. G., and M. C. Kelley, Ionospheric irregularities, Rev. Geophys. Space Phys., 18(2), 401-454, 1980.

Feldstein, Y. I., and G. V. Starkov, Dynamics of auroral belt and polar geomagnetic disturbances, Planet Space Sci., 15, 209-229, 1967.

Folkestad, K., T. Hagfors, and S. Westerlund, EISCAT: an updated description of technical characteristics and operational capabilities, Radio Sci., 18, 867-879, 1983.

Gadsden, M., On the association of "auroral" radar echoes with aurora, Planet. Space Sci., 15, 693-700, 1967.

Galperin, Y. I., J. Cranier, and Y. V. Lisakov et al., Diffuse auroral zone. 1. The model of equatorward diffuse auroral electron precipitation boundary in the evening and afternoon sectors, Kosmich. Issled., 15, 421-433, 1977.

Georgio, N. V., J. Cranier, J.-A. Sauvand, and V. M. Sinitsin, Diffuse auroral zone. 3. The comparison of the diffuse auroral boundary with plasmapause location during the magnetic storms on February 16 and 17, 1972, Kosmich. Issled., 16, 937-942, 1978.

Grabowski, R., C. Hanuise, E. Nielsen, J.-P. Villain, and H. Wolf, Simultaneous measurements of the ionospheric electric field by probe and radar method, J. Atmos. Terr. Phys., 47, 41-48, 1985.

Greenwald, R. A., W. L. Ecklund, and B. B. Balsley, Auroral currents, irregularities and luminosity, J. Geophys. Res., 78, 8193-8203, 1973.

Greenwald, R. A., W. L. Ecklund, and B. B. Balsley, Radar observations of auroral electrojet currents, J. Geophys. Res., 80, 3635-3641, 1975. 
Greenwald, R. A., K. B. Baker, and J.-P. Villain, Initial studies of small-scale $\mathrm{F}$ region irregularities at very high latitudes, Radio Sci., 18, 1122-1132, 1983.

Greenwald, R. A., K. B. Baker, R. Hutchins, and C. Hanuise, An HF phased-array for studying small-scale structure in highlatitude ionosphere, Radio Sci., 20, 63-79, 1985.

Greenwald, R. A., K. B. Baker, J. R. Dudeney, M. Pinnock, T. B. Jones, E. C. Thomas, J.-P. Villain, J.-C. Cerisier, C. Senior, C. Hanuice, R. D. Hunsucker, G. Sofko, J. Koehler, E. Nielsen, R. Pellinen, A. D. M. Walker, N. Sato, and H. Yamagishi, DARN/ SUPERDARN, Space Sci. Rev., 71, 761-796, 1995.

Gussenhoven, M. S., D. A. Hardy, and W. J. Burke, DMSP/F2 electron observation of equatorward auroral boundary and their relationship to magnetospheric electric fields, J. Geophys. Res., 86, 768-778, 1981.

Gussenhoven, M. S., D. A. Hardy, and N. Heinemann, Systematics of the equatorward diffuse auroral boundary, J. Geophys. Res., 88, 5692-5704, 1983.

Hall, G. E., J. W. MacDougal, D. R. Moorcroft, J.-P. St-Maurice, A. H. Manson, and C. E. Meek, Super dual auroral radar network observation of meteor echoes, J. Geophys. Res., 102, 14 603-14 614, 1997.

Herlofson, N., Interpretation of radio echoes from polar aurora, Nature, 160, 867-868, 1947.

Holzworth, R. H., and C.-I. Meng, Mathematical representation of auroral oval, Geophys. Res. Lett., 2, 377-380, 1975.

Hultqvist, B., and A. Egeland, Radio aurora, Space Sci. Rev., 3, 27 $78,1964$.

Ivanov, V. E., A. S. Kirillov, M. V. Mal'kov, T. I. Sergienko, and G. V. Starkov, The auroral oval boundaries and planetary model of luminous intensity, Geomagn. Aeron., 33(5), 630-636 (in English), 1993.

Karlsson, S. B. P., H. J. Opgenoorth, P. Eglitis, K. Kauristie, M. Syrjäsuo, T. Pulkkinen, M. Lockwood, R. Nakamura, G. Reeves, and S. Romanov, Solar wind control of magnetospheric energy content: Substorm quenching and multiple onsets, J. Geophys. Res., 105, 5335-5356, 2000.

Knox, F. B., A contribution to the theory of the production of fieldaligned ionisation irregularities in equatorial electrojet, J. Atmos. Terr. Phys., 26, 239-249, 1964.

Kustov, A., M. Uspensky, J. Kangas, A. Huuskonen, and E. Nielsen, On the threshold electric field for the $1-\mathrm{m}$ auroral irregularity appearance, J. Geophys. Res., 94, 12 043-12 048, 1989.

Lui, A. T. Y., P. Perreault, S.-J. Akasofu, and C. D. Anger, The diffuse aurora, Planet. Space Sci., 21, 857-861, 1973.

Lui, A. T. Y., C.-J. Meng, and S. Ismail, Large amplitude undulation on the equatorward boundary of the diffuse aurora, J. Geophys. Res., 87, 2385-2400, 1982.

Liou, K., P. T. Newell, C.-I. Meng, M. Brittnacher, and G. Parks, Synoptic auroral distribution: a survey using Polar ultraviolet imagery, J. Geophys. Res., 102, 27 197-27 205, 1997.

Mattin, N., and T. B. Jones, Propagation angle dependence of radar auroral E-region irregularities, J. Atmos. Ter. Phys., 49, 115-121, 1987.

Milan, S. E., T. B. Jones, T. R. Robinson, E. C. Thomas, and T. K. Yeoman, Interferometric evidence for the observation of ground backscatter originating behind the CUTLASS coherent HF radars, Ann. Geophysicae, 15, 29-39, 1997.

Milan, S. E., T. K. Yeoman, M. Lester, E. C. Thomas, and T. B. Jones, Initial backscatter occurrence statistics from the CUTLASS HF radars, Ann. Geophysicae, 15, 703-718, 1997.

Milan, S. E., T. K. Yeoman, and M. Lester, The dayside auroral zone as a hard target for coherent HF radars, Geophys. Res. Lett., 25, 3717-3720, 1998.

Milan, S. E., M. Lester, S. W. H. Cowley, J. Moen, P. E. Sandholt, and C. J. Owen, Meridian-scanning photometer, coherent HF radar, and magnetometer observations of the cusp: a case study, Ann. Geophysicae, 17, 159-172, 1999.

Moller, H. G., Backscatter results from Lindau, II, The movements of curtains of intense irregularities in the polar $F$ layer, J. Atmos. Terr. Phys., 36, 1487-1501, 1974.
Pudovkin, M. I., S. A. Zaitseva, T. A. Kornilova, and R. I. Pellinen, Auroral dynamics in the equatorward edge of the auroral zone, Geomagn. Aeron., 35(3), 339-344 (in English), 1995.

Rino, C. L., R. C. Livingston, R. T. Tsunoda, R. M. Robinson, J. F. Vickrey, C. Senior, M. D. Cousins, J. Owen, and J. A. Klobuchar, Recent studies of the structure and morphology of auroral zone F region irregularities, Radio Sci., 18, 1167-1180, 1983.

Rodger, A. S., S. B. Mende, T. J. Rosenberg, and K. B. Baker, Simultaneous optical and HF radar observations of the ionospheric cusp, Geophys. Res. Lett., 22, 2045-2048, 1995.

Senior, C., R. M. Robinson, and T. Potemra, Relationship between field-aligned currents, diffuse auroral precipitation and westward electrojet in early morning sector, J. Geophys. Res., 87, 10 469-10 477, 1982.

Slater, D. W., L. L. Smith, and E. W. Kleckner, Correlated observations of equatorward diffuse auroral boundary, J. Geophys. Res., 85, 531-542, 1980.

Starkov, G. V., Mathematical model of the auroral boundaries, Geomagn. Aeron., 34(3), 331-336 (in English), 1994.

Starkov, G. V., and M. V. Uspensky, Substorm in radio aurora, Geomagn. Aeron., 28(5), 662-665 (in English), 1988.

Syrjäsuo, M., New Finnish all-sky cameras, in Proceedings of the 24th Optical Meeting in Andenes, Norway, 1997.

Tsunoda, R. T., High-latitude F region irregularities: a review and synthesis, Rev. Geophys., 26(4), 719-760, 1988.

Tsunoda, R. T., and E. J. Fremouw, Radar auroral substorm signatures: 2. East-west motion, J. Geophys. Res., 81(A34), 6159-6168, 1976

Tsunoda, R. T., R. I. Presnell, R. L. Leadabrand, Radar auroral echo characteristics as seen by $398 \mathrm{MHz}$ phase array radar operated at Homer, Alaska, J. Geophys. Res., 79, 4709-4724, 1974

Tsunoda, R. T., R. I. Presnell, Y. Kamide, and S.-I. Akasofu, Relationship of radar aurora, visual aurora and auroral electrojets in the evening sector, J. Geophys. Res., 81, 60056015, 1976.

Unwin, R. S., and C. Cummack, Drift spikes: The ionospheric signatures of large poleward directed electric fields at subauroral latitudes, Mem. Nat. Inst. Polar Res., Tokyo, 16, 72-83, 1980.

Uspensky, M. V., R. A. Greenwald, K. Kaila, A. V. Kustov, R. J. Pellinen, E. V. Pudovkina, O. M. Raspopov, and G. V. Starkov, Eastward radar aurora and auroral loop motion in the morning sector, in Studies of the high-latitude ionosphere and magnetosphere, Nauka, Leningrad, 41-55 (in Russian), 1982.

Uspensky, M. V., R. J. Pellinen, W. Baumjohann, G. V. Starkov, E. Nielsen, G. Sofko, and K. Kaila, Spatial variations of ionospheric conductivity and radar auroral amplitude in the eastward electrojet region during pre-substorm condition, J. Geophys., 52, 40-48, 1983.

Uspensky, M. V., and G. V. Starkov, Aurora and auroral radar backscatter, Nauka, Leningrad, 239 (in Russian), 1987.

Uspensky, M. V., and P. J. S. Williams, The amplitude of auroral backscatter-1. Model estimates of the dependence on electron density, J. Atmos. Terr. Phys., 50, 73-79, 1988.

Uspensky, M. V., G. V. Starkov, O. Aulamo, and K. Kaila, Breakup signatures in the VHF auroral radar backscatter and optical emissions, in Proceedings of the International Conference on Substorms, Kiruna, ESA SP-335, 337-342, 1992.

Uspensky, M. V., A. V. Kustov, G. J. Sofko, J. A. Koehler, J.-P. Villain, C. Hanuice, J. M. Ruohoniemi, and P. J. S. Williams, Ionospheric refraction effects in slant range profiles of auroral HF coherent echoes, Radio Sci., 29(2), 503-517, 1994.

Villain, J.-P., R. A. Greenwald, K. B. Baker, and J. M. Ruohoniemi, HF radar observations of $E$ layer plasma irregularities produced by oblique electron streaming, J. Geophys. Res., 92(A11), 12 327-12 342, 1987. 
Weber, E. J., R. T. Tsunoda, J. Buchau, R. E. Sheehan, D. J. Strickland, W. Writing, and J. G. Moore, Coordinated measurements of auroral zone plasma enhancements, J. Geophys. Res., 90, 6497-6513, 1985.
Yeoman, T. K., M. Lester, S. W. H. Cowley, S. E. Milan, J. Moen, and P. E. Sandholt, Simultaneous observation of the cusp in optical, DMSP and HF Radar data, Geophys. Res. Lett., 24, 2251-2254, 1997. 